\title{
Os desafios do direito à saúde na sociedade complexa
}

The challenges of the right to health in complex society

\section{Marina Sanches Wünsch}

Advogada. Mestranda em Direito. Grupo de Pesquisa Direito Sanitário no Rio Grande do Sul, Fundação de Apoio à Pesquisa do Estado do Rio Grande do Sul. Porto Alegre, Brasil.

\section{Sandra Regina Martini Vial}

Pós-Doutora em Direito. Professora da Universidade do Vale do Rio dos Sinos e da Scuola Dottorale Internazionale Tullio Ascarelli; Professora visitante da Università Degli Studi di Salerno. Pesquisadora produtividade CNPq. Porto Alegre, Brasil.

Resumo: Neste trabalho nos ocuparemos das mudanças ocorridas nas últimas décadas, quando presenciamos inúmeras descobertas científicas relacionadas às ciências da vida, ao mesmo tempo em que assistimos a conquista dos Direitos Sociais, mais especificamente do direito à saúde, através da Constituição de 1988, reflexo de inúmeros movimentos sociais. Todos esses avanços repercutem na sociedade atual, que passa a ser cada vez mais complexa diante de tantas possibilidades, e impacta na formação de novas áreas do conhecimento como a bioética. Com isso, compreende-se que as descobertas científicas, a bioética e o direito à saúde vão avançando conjuntamente. Dessa forma, trataremos de analisar como o sistema da saúde se organiza ou não para responder aos avanços das novas tecnologias em matéria de saúde e como isso reflete no Sistema do Direito.

Palavras-chaves: Sociedade complexa; avanços tecnocientíficos; direito à saúde; judicialização.

Key-words: Complex Society; technoscientific advances; Right to Health; Jjudicialization.

\section{Introdução}

A atual sociedade é caracterizada como uma sociedade complexa, contingente, com diversos limites e possibilidades, decorrência das últimas décadas de desenvolvimento, especialmente, da tecnocientífica, que possibilitou inúmeras descobertas científicas relacionadas às ciências da vida, como por exemplo, as descobertas de tratamentos para doenças, preservação da vida sobre condições artificiais, a clonagem, a eutanásia, a robótica, dentre outros. 
O impacto destas descobertas foi muito significativo e demandou a formação de novas áreas do conhecimento como: a bioética, o biodireito, a biopolítica, o biopoder, etc, que exigem cada vez mais dos profissionais em saúde, uma postura transdisciplinar, já que a sociedade atual é cada vez mais complexa e, portanto, limitar a realidade a um único olhar ou disciplina significa reduzir a realidade.

Ademais, esta alta complexidade/paradoxalidade da sociedade atual foi, ao mesmo tempo, incrementada pela conquista dos direitos sociais através da constitucionalização em 1988, reflexo de inúmeros movimentos sociais, sobretudo do movimento sanitarista, portanto, o Direito à saúde se consagra neste mesmo período, cuja previsão legal encontra-se no art. 196 da nossa Constituição Federal.

Assim, todas essas transformações sociais exigem uma evolução do olhar, dos conceitos, das crenças, reflexões éticas no tocante a sua aplicação prática, uma vez que o ser humano se coloca diante de inúmeros dilemas como, por exemplo: se temos tantas novas tecnológias, tantos medicamentos, não teríamos o direito de utiliza-los até o limite para aumentar a expectativa de vida, salvar vidas ou melhorar a qualidade de vida? Quem tem direito ao acesso a essas tecnologias? Somente quem pode pagar? Ou todo ser humano deveria ter acesso? Se um medicamento que se encontra na Relação Nacional de Medicamentos Essenciais disponibilizados pelo Sistema Único de Saúde não tenha o efeito pretendido, não teria essa pessoa o direito de obter o medicamento mais adequado, mais avançado?

Com isso, compreende-se que as descobertas científicas e o Direito à saúde vão avançando e consequentemente, o avanço científico reflete diretamente na efetivação do Direito à saúde, pois este Direito Fundamental ao mesmo tempo precisa acompanhar os avanços desta sociedade tecnocientífica. Contudo, o Sistema da Saúde ainda não está suficientemente organizado no sentido de responder a estas demandas de saúde cada vez mais avançadas, o que acaba por desembocar no poder judiciário que passa a ter que decidir em demandas que reivindicam, por exemplo, o uso de novos medicamentos, tratamentos, a utilização de novas tecnológias - dando escopo à denominada judicialização da saúde.

Desse modo, este artigo pretende inicialmente situar o marco do Direito Sanitário e da denominada sociedade tecnocientífica, uma vez que, são os dois pontos de partidas para posteriormente se analisar a questão da judicialização sobre o enfoque das novas tecnologias em termos de saúde. Em seguida, abordaremos o 
tema da regulamentação das novas tecnologias no Sistema Único de Saúde e, por fim, trataremos de analisar como o sistema da saúde se organiza ou não para responder aos avanços das novas tecnologias em matéria de saúde e como isso reflete no sistema do direito, através da judicialização.

\section{A relação do direito à saúde e da biotecnologia na sociedade complexa}

$\mathrm{Na}$ década de 70, a combinação genética e a recombinação do DNA, base tecnológica da engenharia genética possibilitou a aplicação de conhecimento cumulativo na área da biotecnologia, dando inicio a uma revolução biotecnológica; é partir dos anos 70, por exemplo, que o primeiro gene humano foi clonado (Castells, 2001, p. 65).

Assim, nesse contexto, a tecnociência passa a possibilitar à ação humana o exercício de poderes em dimensões nunca antes imaginadas. O potencial da intervenção humana na natureza não só foi incrementado quantitativamente, como também qualitativamente. O homem passou a manipular a sua própria natureza, bem como a natureza extra-humana, tornando imprevisíveis, em muitos casos, as consequências das suas ações (Barreto e Mello, 2009, p. 30).

Ainda com relação aos inúmeros avanços, mais especificamente no controle de doenças, um fluxo contínuo de genes humanos relacionados a várias doenças estão sendo identificados, desse modo, segundo Castells:

Com certeza, isso cria a possibilidade de ação nesses genes e nos outros que serão identificados no futuro, tornando a espécie humana capaz não apenas de controlar algumas doenças, mas de identificar predisposições biológicas e nelas intervir, portanto alterando potencialmente o destino genético (Castells, 2001, p. 66).

Ora, questões como banir algumas doenças, como de patentes e direitos legais sobre conhecimento e mapeamento do genoma humano preocupam, pois ainda não temos respostas e todos estes avanços envolvem questões muito mais complexas, que o ser humano ainda precisa refletir e aprender. Além disso, se trata de uma grande quantidade de conhecimento limitado nas mãos de poucos e o perigo esta justamente em passar a tratar da questão mais como uma disputa comercial do que de difusão e progresso deste conhecimento de modo a beneficiar a sociedade.

Portanto, segundo Barretto, na sociedade tecnocietífica, a ação humana se identifica com a ação técnica, produzindo efeitos que não podem ser determinados como "bons" ou "maus" através de distinções qualitativas evidentes por si. Refere-se 
à possibilidade do homem interferir na liberdade intrínseca dos organismos e no dinamismo da vida - por meio de técnicas como a manipulação genética, a biotecnologia e a nanotecnologia - transforma, assim, a compreensão do homem e da natureza (Barreto e Mello, 2009, p. 31, 36 e 39).

Diante de tantos avanços tecnológicos, o estudo da bioética surge, justamente, para tratar dos desafios éticos do desenvolvimento tecnológico na área da saúde e dos progressos da ciência biológica e sua interação na relação médico paciente. Segundo Garrafa a bioética é baseada "na multi, inter e transdisciplinariedade, na secularização dos costumes e na necessidade de respeito ao pluralismo moral constatado nas sociedades contemporâneas, para ela, o que vale é o desejo livre, soberano e consciente dos indivíduos e das sociedades humanas, desde que as decisões não invadam a liberdade e os direitos de outros indivíduos e outras sociedades" (Garrafa, 2008, p. 425).

Enquanto isso, na América Latina, em meados dos anos 70, dava-se os primeiros passos em direção a uma longa caminhada de luta pela saúde pública. Esta luta pela saúde e os frutos dela tiveram inicio com o movimento sanitarista que aconteceu em toda América Latina e foi influenciado pelo modelo da Reforma Sanitária Italiano.

O movimento era um conjunto de pessoas com idéias comuns para o campo da saúde, portanto, tratava-se de um grupo restrito de intelectuais, médicos e lideranças políticas do setor saúde. Este grupo influenciou fundamentalmente o âmbito acadêmico e pode ser considerado como o mentor do processo de reformulação do setor.

No caso do Brasil, o descaso político-jurídico com a saúde era de longa data; as Constituições de 1824 e 1891 não tratavam de tal temática, já no texto constitucional de 1934 a preocupação não era com a saúde propriamente dita, enquanto direito fundamental, mas sim com o combate às doenças, visto que isso poderia causar prejuízos aos negócios de exportação do Brasil. Ademais, até a Lei Orgânica da Previdência Social de 1960 não tínhamos a unificação dos Institutos de Pensão e Aposentadoria e durante o período da ditadura militar tivemos um crescimento da iniciativa privada bem como o modelo de atenção hospitalocêntrico, ou seja, cada Instituto criava seu hospital próprio financiado muitas vezes também com dinheiro público (Vial, 2010, p. 07). É somente nos anos 80, que o movimento 
sanitário começa a denunciar várias irregularidades no sistema da saúde e da previdência.

Assim, a constitucionalização do Direito à saúde no Brasil é resultado da mobilização de grupos sociais em prol do reconhecimento de novos direitos sociais, como meio de diminuir as desigualdades sociais e restabelecer a democracia. Contudo, embora o movimento sanitarista tenha ocorrido concomitante ao surgimento da bioética, segundo Junges: "a bioética não participa dessa discussão, porque está enfocada nos aspectos clínicos e preocupada com os avanços das biotecnologias aplicadas ao ato médico" (Junges, 2006, p. 255).

As discussões bioéticas difundem-se na América Latina somente a partir da década de 1990, não obstante, explica Pavoni, que a difusão da bioética em direção aos países do hemisfério sul, contribuiu de maneira significativa para incluir a coletividade na discussão bioética, vejamos:

\begin{abstract}
Neste período, a difusão da bioética em direção aos países do hemisfério sul, especialmente a América Latina, onde convivem ilhas de excelência tecnológica em saúde com a extrema pobreza da maioria das populações, torna imperativa a inclusão dos problemas da coletividade na agenda das discussões, com temas como o acesso aos serviços de saúde, a alocação de recursos em saúde, as questões demográficas e populacionais e a responsabilidade social e coletiva sobre as condições de saúde (Pavoni, 2012, p. 34).
\end{abstract}

Em vista disso, na atualidade se percebe que é preciso ampliar as discussões bioéticas para uma perspectiva coletiva que leve em consideração a saúde coletiva, ou seja, analisar a vida em sentido amplo. Assim, ao ressaltar as preocupações com as dimensões sociais dos problemas, Junges vai afirmar que no século XX "a novidade está em que a preocupação não se restringiu apenas à prevenção, mas se estende também à promoção da saúde. Este não é só um objetivo da medicina, mas da sociedade como um todo" (Junges, 2006, p. 257).

Um dos reflexos desta mudança é que com a implementação do SUS no Brasil passou-se a usar o termo "saúde coletiva" no lugar de "saúde pública" e, a bioética precisara acompanha estas mudanças em relação à saúde. O nosso Sistema Único de Saúde (SUS) criado em 1990, através da Lei 8.080, representa uma grande evolução para o Direito à saúde no Brasil, já que é um sistema público e nacional, baseado no princípio da universalidade.

Desse modo, segundo Junges, é no contexto do SUS que se ampliam os "desafios éticos-sociais da saúde" (Junges, 2006, p. 253), pois, no caso do Brasil, o 
conteúdo do Direito à saúde, expresso no princípio constitucional brasileiro: "A saúde é um direito de todos e um dever do Estado", não é em si a saúde, mas o acesso aos meios terapêuticos necessários para recuperar a saúde possível em determinada situação clínica e, portanto, expressa o princípio da equidade (Junges, 2006, p. 259).

Ou seja, a questão de acesso ao serviço de saúde coloca os administradores, o Estado, os profissionais em saúde diante de dilemas éticos, principalmente os relacionados ao desenvolvimento da biotecnologia.

\section{A Regulação das novas tecnologias em saúde no Brasil}

O Sistema Único de Saúde Brasileiro é orientado pelos melhores princípios que se poderia pensar em termos de organização da saúde que são: universalidade de acesso e integralidade de atendimento. Além disso, sua estrutura organizacional é excelente, pois prevê um sistema que integra as três esferas da federação, de forma que todos os entes são solidariamente obrigados a prestar este atendimento e, por isso, como sistema, é reconhecido como um dos melhores do mundo.

Contudo, o fato de possuirmos um sistema universal, integral, equânime, integrado e hierarquizado faz com que seja necessário um número abrangente de ações em saúde. Além disso, compreende-se que as descobertas científicas e o Direito à saúde vão avançando ao mesmo tempo e, portanto, é preciso verificar como o avanço científico reflete diretamente na efetivação do Direito à saúde, pois este Direito Fundamental ao mesmo tempo precisa acompanhar os avanços desta sociedade tecnocientífica. Assim, esses movimentos fazem com que o sistema, muitas vezes, não de conta de garantir o Direito à saúde e, ao mesmo tempo, exige que este progressivamente defina programas e ações prioritárias de saúde.

As tecnologias em saúde incluem, além dos equipamentos médicos, os produtos para a saúde, os medicamentos, as vacinas, os testes diagnósticos, as órteses e próteses, e inúmeros materiais e sistemas informacionais de aplicação na assistência à saúde. São insumos que podem demandar o emprego de cadeias de tecnologias para monitoramento e controle, e geralmente são dedicados a grupos restritos de pacientes de alta vulnerabilidade, cuja aplicação ao tratamento venha possibilitar e/ou favorecer a melhoria do cuidado (Petramale, 2011, p. 993).

Assim, o desenvolvimento da biotecnologia acrescentam novos dilemas a este panorama da Saúde Pública no Brasil: Qual o limite ao acesso integral? Tem o SUS a 
obrigação de oferecer todo o acesso às tecnologias em saúde? Quais as limitações do acesso integral? Como o SUS tem avançado para ampliar o acesso às tecnologias?

O SUS engloba importantes ações de prevenção e assistência que são determinantes na qualidade de vida da população, uma dessas ações, por exemplo, insere-se o componente da Assistência Farmacêutica - parte integrante da Política Nacional de Medicamentos (PNM), assim, esta envolve o abastecimento de medicamentos, o controle de qualidade, a segurança e a eficácia terapêutica dos medicamentos, a obtenção e a difusão de informações sobre medicamentos, a educação permanente de profissionais de saúde, do paciente e da comunidade para assegurar o uso racional de medicamentos etc. (Aith et al., 2010 a, p. 266-267).

Para decidir sobre incorporação de tecnologias, o Ministério da Saúde criou o Departamento de Gestão e Incorporação de Tecnologias que aloca a Secretaria Executiva da Comissão Nacional de Incorporação de Tecnologias no SUS. A CONITEC é regida pela Lei oㅜ 12.401, de 28 de abril de 2011, que altera a Lei $n^{\circ}$ 8.080 de 19 de setembro de 1990, para dispor sobre a assistência terapêutica e a incorporação de tecnologia em saúde no âmbito do Sistema Único de Saúde (SUS), pois segundo o próprio Ministério da Saúde é preciso que ajam critérios técnicos para a incorporação de novas tecnologias e medicamentos no SUS.

Desse modo, a Lei 12.401/2011, complementa o texto constitucional, estabelecendo os procedimentos e alguns critérios para a incorporação das novas tecnologias em saúde, especialmente, no sentido de garantir que só serão incorporadas as tecnologias e os tratamentos que comprovaram ser efetivos e seguros e qual o custo-efetividade ${ }^{1}$.

Atualmente, estão em discussão à solicitação de incorporação de inúmeras novas tecnologias, como por exemplo, da vacina contra HPV, da ambrisentana para o tratamento da hipertensão arterial pulmonar, da bengala de quatro pontas na Tabela

\footnotetext{
${ }^{1}$ Conforme dispõe o art. 19-Q da referida lei: $\S 2^{\circ}$ O relatório da Comissão Nacional de Incorporação de Tecnologias no SUS levará em consideração, necessariamente: I - as evidências científicas sobre a eficácia, a acurácia, a efetividade e a segurança do medicamento, produto ou procedimento objeto do processo, acatadas pelo órgão competente para o registro ou a autorização de uso; II - a avaliação econômica comparativa dos benefícios e dos custos em relação às tecnologias já incorporadas, inclusive no que se refere aos atendimentos domiciliar, ambulatorial ou hospitalar, quando cabível. (grifo nosso)
} 
de Procedimentos, Medicamentos e OPM, etc. Assim, a modernização do sistema é uma preocupação constante.

Além disso, percebe-se que as disposições legais, ressaltam o papel do estado em uma dimensão defensiva e prestacional da dignidade da pessoa humana, pois, como afirma Sarlet:

Como limite, a dignidade implica não apenas que a pessoa não pode ser reduzida à condição de mero objeto da ação própria e de terceiros, mas também o fato de [que] a dignidade gera direitos fundamentais (negativos) contra atos que a violem ou a exponham a graves ameaças. Como tarefa, da previsão constitucional (explícita ou implícita) da dignidade da pessoa humana, [...] decorrem deveres concretos de tutela por parte dos órgãos estatais, no sentido de proteger a dignidade de todos, assegurando-lhe também por meio de medidas positivas (prestações) o devido respeito e promoção (Sarlet, 2010, p. 148).

E esse papel do Estado é fundamental, pois, nesse novo contexto da sociedade tecnocientífica, a ação humana produz efeitos indeterminados, tanto bons como ruins. Aqui reside o novo paradigma sugerido por Hans Jonas, que implica em considerar a coexistência dos efeitos benéficos e maléficos convivendo na ação humana. Existe um laço ameaçador que a técnica produz, não só quando é utilizada com abuso e má vontade, mas também quando bem empregada em fins legítimos (Barreto, 2010, p. 357).

Assim, esta legislação é uma resposta jurídico-política às questões bioéticas que surgem com as novas tecnologias no âmbito do SUS, pois, a decisão a respeito da incorporação de uma tecnologia pelo sistema de saúde, seja público ou privado, devem considerar aspectos éticos, uma revisão sistemética, análise econômica, segurança tecnológica.

Além disso, é preciso lembrar que a utilização destas novas tecnologias exige a capacitação de profissionais para a realização das avaliações cientificamente embasadas, onde desempenha um papel muito importante a Agência Nacional de Vigilância Sanitária, a Agência Nacional de Saúde Suplementar, os governos estaduais e municipais, hospitais de ensino e hospitais de excelência.

Mas, apesar de toda essa regulamentação que vêm sendo introduzida e do esforço para acompanhar os avanços tecnológicos, é importante lembrar, que existe um limite ao acesso integral previsto no capítulo da saúde da Constituição Brasileira, como afirma Henriques, o acesso integral: 
Não pode ser interpretado como "todas as tecnologias oferecidas no mercado para todas as pessoas", o que além de inviável em qualquer sistema de saúde, multiplicaria os riscos de procedimentos de indicação duvidosa. A sociedade e os gestores da saúde têm procurado identificar necessidades reais de saúde, avaliar as tecnologias existentes, eleger prioridades e organizar o acesso aos serviços e produtos (Henriques, 2009).

$\mathrm{Na}$ questão dos medicamentos, é quase impossível que a lista de medicamentos do SUS preveja todos os medicamentos existentes no mundo, uma vez que, as descobertas científicas e os avanços tecnológicos são muito mais rápidos que os debates bioéticos a respeito da nova descoberta, que legislação, já que:

Sempre que um produto ou procedimento é introduzido, devem existir regras que estabeleçam precisamente as circunstâncias e condições de indicação, forma de utilização, critérios de acompanhamento e interrupção. São os protocolos ou diretrizes clínicas, para orientar condutas e decisões dos profissionais de saúde, que podem não ter convivido, durante sua formação, com técnicas recentes e raramente têm acesso às informações no tempo necessário (Henriques, 2009).

Além disso, outro fator que contribui para que a incorporação das novas tecnologias seja muito lenta é a burocracia estatal. Com isso, o processo de abreviamento deste tempo muito longo para incorporação e que contribui para que as tecnologias sejam incorporadas rapidamente, muitas vezes, acaba por ser a via judicial.

Assim, evidente, que um acesso integral não se restringe a ter um acesso a todas às tecnologias em saúde, a tecnologia somente será eficaz e segura acompanhada de um bom diagnóstico clínico, a indicação do esquema terapêutico apropriado, o acolhimento e os cuidados nas dimensões físicas, psíquicas e sociais que fazem a diferença na atenção à saúde das pessoas. Desse modo, oferecer atenção integral e universal à saúde, como é a missão do SUS, é muito mais do que simplesmente oferecer acesso a tecnologias em saúde (Petramale, 2011, p. 993). Por outro lado, um tratamento que, para ser efetivo, necessitada de determinada tecnologia não pode depender da capacidade econômica do cidadão para determinar quem vai ter acesso ou não às novas tecnologias.

\section{Os desafios do direito à saúde: a judicialização da saúde}

O Sistema Único da Saúde Brasileiro vem evoluindo muito, porém ainda não está suficientemente organizado no sentido de responder a demandas de saúde cada vez mais avançadas, até porque a lei 12.401/20122, que dispõe sobre a assistência 
terapêutica e a incorporação de tecnologia em saúde no âmbito do Sistema Único de Saúde é muito recente. Além disso, a construção de um sistema de saúde envolve a necessidade de toda uma estruturação do sistema, de definições e estatuição de programas governamentais e de ações intersetoriais, especialmente, para incorporar de forma mais emergente os avanços científicos da área da saúde.

Assim, inúmeras demandas em saúde acabam por desembocar no poder judiciário que passa a ter que decidir em demandas que reivindicam o uso de novos medicamentos, tratamentos e tecnologias - dando escopo à denominada judicialização da saúde. Ocorre que, no caso do Direito à saúde, as tecnologias podem também causar riscos e incertezas para a sociedade e se tornar atos abusivos contra o ser humano, aparecendo, desse modo, muitos dilemas éticos e jurídicos, que colocam os juízes em uma posição conflitante, pois este tem a obrigação de decidir, entre dar ou não um medicamento, um leito, um tratamento, em sua grande maioria em demandas de urgência.

Segundo Aith, dentre os Direitos garantidos pela Constituição de 1988, o Direito à saúde se destaca de duas formas: como direito social que é, possui a característica de exigir do Estado brasileiro ações concretas e efetivas para a promoção, proteção e recuperação da saúde e, de outro lado, como um direito subjetivo público, na medida em que permite que o cidadão ingresse com uma ação judicial para exigir do Estado ou de terceiros legalmente responsáveis, a adoção ou abstenção de medidas concretas em favor da saúde (Aith, 2010 b, p. 185).

Sob o ponto de vista do Direito à saúde como um direito subjetivo público, a judicialização predominante envolve medicamentos em geral de alto valor e não previstos nas listas de medicamentos do SUS, ações voltadas para obtenção de hospitalização, cirurgias, produtos médicos, alimentação especial, e medicamentos de menor valor, por questões relacionadas à gestão da saúde ou por falta de medicamentos em estoque. Trata-se, portanto, da questão da incorporação de novas tecnologias em saúde.

Como dito anteriormente, a incorporação das novas tecnologias no SUS é muito lenta, pelo fato da burocracia estatal ser muito pesada e é difícil que a lista preveja todos os medicamentos existentes, então, não é raro um paciente precisar de um tratamento que necessite de um medicamento que está em falta ou que não é fornecido pelo SUS e não tem condições financeiras próprias de adquirir o 
medicamento, assim, é uma consequência natural que, excepcionalmente, as pessoas busquem no judiciário um direito social, constitucionalizado, no sentido de corrigir o rumo da politica pública.

A consequência é que são ações individuais e não coletivas e, portanto, somente parte da população consegue ter acesso a um determinado medicamente, tratamento, pois ingressou no judiciário com o pedido, enquanto muitos simplesmente ficam sem esse Direito Fundamental à Saúde, à dignidade e, às vezes, sem o direito à vida. E, ao ingressar no Judiciário, por tratar-se de um Direito Fundamental, na primeira instância, a grande maioria das decisões é no sentido de conceder o pedido liminarmente, tendo em vista a urgência do pedido, e determina ao Poder Executivo o fornecimento do medicamento.

De qualquer modo, o grande número de demandas judiciais em saúde pode tornar-se um mecanismo de pressão do poder público, para que medidas para a implementação do Direito à saúde sejam tomadas de forma mais rápida. Neste cenário, Aith explica o papel da "judicialização em saúde":

Neste cenário, onde se confrontam indicações médicas, custos elevados e recursos limitados, os planos privados de saúde e as famílias têm pressionado o Poder Público a se responsabilizar e arcar, sobretudo, com os custos terapêuticos. A complexidade deste fenômeno, denominado "judicialização da saúde" - por suscitar a interface entre esferas do Poder Público, confrontadas no desafio constitucional de garantir os direitos universais dos cidadãos à atenção integral à saúde -, repercute no constrangimento dos gestores do sistema, frente aos mecanismos jurídicos que visam garantir aos pacientes/usuários a assistência médica recomentada (Aith et al., 2010 a, p. 269).

As ações judiciais aceleram o processo de incorporação das novas tecnologias, pois na medida em que as tecnologias passam a integrar a lista publica, as aquisições passam a ser feitas de forma mais regular, com emprego de licitações e não com compras individuais, como é feito nas ações judicias, por isso, o gestão muitas vezes analisando o custo beneficio acaba por integrar na politica publica a nova tecnologia. São exemplos positivos da judicialização a incorporação do coquetel para tratamento do HIV, a incorporação de medicamento para o tratamento da Hepatite C, dentre outros.

Diante da crescente judicialização em saúde foi realizada a Audiência Pública № 04 do STF, esta é considerada um marco importante no Poder Judiciário em geral no que diz respeito ao direito à saúde, pois se ouviu 50 especialistas em saúde, entre 
advogados, defensores públicos, promotores e procuradores de justiça, magistrados, professores, médicos, técnicos de saúde, gestores e usuários do sistema único de saúde, objetivando esclarecer as questões técnicas, científicas, administrativas, políticas, econômicas e jurídicas relativas às ações de prestação de saúde.

A audiência culminou na aprovação da Recomendação n. 31, de 30 de março de 2010, pelo Plenário do $\mathrm{CNJ}$, que traça diretrizes aos magistrados quanto às demandas judiciais que envolvem a assistência à saúde. Além disso, o CNJ criou o Fórum Nacional da Saúde, composto do Comitê Nacional e de Comitês Estaduais. Entre as atividades dos Comitês Estaduais, está o monitoramento das ações de saúde.

A audiência, portanto, reforça o impacto das descobertas tecnocientífica e seu reflexo no Direito à saúde e na judicialização, o que exige cada vez mais do profissional em saúde (operadores do direito, médicos, gestores) uma postura transdisciplinar, já que a sociedade atual é cada vez mais complexa e, portanto, limitar a realidade a um único olhar ou disciplina significaria reduzir a realidade.

\section{Conclusão}

Ao constatar que o desenvolvimento biotecnológico, a bioética e o Direito à saúde têm início e vão avançando no mesmo período, percebemos que a sociedade vai se tornando mais complexa. Além disso, no Brasil, o fato de garantirmos o Direito à saúde constitucionalmente e possuirmos um Sistema Único de Saúde que prevê acesso universal e integral faz com que os avanços da biotecnologia acrescentem novos dilemas a este panorama da Saúde Pública, pois, a burocracia estatal nesta área faz com que a incorporação de novas tecnologias seja muito lenta.

Os avanços biotecnológicos expõe a crescente vulnerabilidade dos sistemas universais de saúde, pela dificuldade de incorporação de tecnologias essenciais para a promoção, a prevenção e a atenção à saúde. Por outro lado, o Brasil tem avançando nesse sentido, especialmente, após a Lei 12.401/2011, que estabelece os procedimentos e alguns critérios para a incorporação das novas tecnologias em saúde.

Contudo, a judicialização, ainda, reflete uma demanda da sociedade, que encontra na ação judicial uma resposta mais rápida e efetiva para o provimento de um tratamento, medicamento, internação, do que no próprio sistema de saúde, pois o 
sistema do direito é obrigado a decidir, ou seja, produzir decisões legais. Isso se deve a uma desorganização do sistema de saúde, que ainda não está efetivamente estruturado para responder a demandas tão complexas como as desta sociedade atual e acaba por irritar o sistema do direito.

Portanto, a judicialização é reflexo de uma irritação sistêmica, ou seja, onde o sistema da saúde ao não cumprir sua função, que é a de garantir o Direito à saúde, provoca uma irritação no sistema do direito que através de seu código legal e ilegal precisa decidir sobre uma demanda de saúde.

Logo, toda a complexidade da sociedade atual exige enfrentar uma realidade distinta e que exige novas soluções jurídicas capazes de atender de forma adequada as novas realidades, as necessidades emergências dos novos direitos, especialmente os relacionados à revolução tecnológica.

E este panorama somente começara a ser resolvido com eficácia através de uma ação intersetorial que envolva a participação das várias instituições envolvidas, quando os operados do direito não enxergarem o processo judicial como único meio de obter uma prestação em saúde, quando houver um diálogo entre o poder judiciário e a bioética.

\section{Referências}

AITH, Fernando et al. Direito sanitário: saúde e direito, um diálogo possível. Belo Horizonte : ESP-MG, 2010 a.

AITH, Fernando. Perspectivas do Direito Sanitário no Brasil: as garantias jurídicas do direito à saúde e os desafios para sua efetivação. Em: SANTOS, Lenir (org.). Direito da saúde no Brasil. Campinas : Saberes Editora, 2010 b.

BARRETTO, Vicente de Paulo. O fetiche dos direitos humanos e outros temas. Rio de Janeiro : Ed. Lumen Juris, 2010.

BARRETTO, Vicente de Paulo; MELLO, Luís Fernando Morais. Ética, biopoder e sociedade tecnocientífica. Revista Direito e Justiça - Reflexões Sociojurídicas; 9(13): p. 30-49, Nov. 2009.

CASTELLS, Manuel. A sociedade em rede. São Paulo: Paz e Terra, 2001. v. 1.

GARRAFA, Volnei. Genoma, pesquisa com seres humanos e biotecnologia: proteção pelo direito. In: COSTA, Alexandre Bernardino [et al.] (orgs.) O direito achado na rua : introdução crítica ao direito à saúde. Brasília: CEAD/ UNB, 2008. p.423-434.

HENRIQUES. Cláudio Maierovich Pessanha. O SUS e a incorporação de novas tecnologias. O Estado de São Paulo, 2009. [on line] Disponível em: http://portal.saude.gov.br/portal/arquivos/pdf/Artigo O SUS e a incorporacao de n ovas tecnologias.pdf. [Acessado em 21 jul. 2013]. 
JUNGES, José Roque. Bioética: hermenêutica e casuística. São Paulo: Loyola, 2006.

PAVONI, Elma L. C Zaboli. Desafios do próximo milênio: bioética e saúde pública. In: CLOTET, Joaquim (Org). Bioética: meio ambiente, saúde pública, novas tecnologias, deontologia médica, direito, psicologia, material genético humano. Porto Alegre: EDIPUCRS, 2012.

PETRAMALE, Clarice Alegre Nova Comissão Nacional de Incorporação de Tecnologias de Saúde e impacto ao Sistema Único de Saúde In: Rev. Saúde Pública vol.45, n.5, 2011 pp. 993-996. [on line] Disponível em http://www.scielosp.org/pdf/rsp/v45n5//Tdecit.pdf [Acessado em 21 jul. 2013]

SARLET, Ingo Wolfgang. Dignidade da Pessoa Humana. In: BARRETO, Vicente de Paulo (cod.). Dicionário de Filosofia Política. São Leopoldo: Ed. Unisinos. 2010.

VIAL, Sandra Regina Martini. Saúde e determinantes sociais: uma situação paradoxal. Revista Comparazione e diritto civile, v. 1, p. 1-24, 2010. [on line] Disponível em http://www.comparazionedirittocivile.it/prova/files/saude martini.pdf [Acessado em 10 jul. 2013]. 